\title{
231 \\ THE EFFECT OF PREOPERATIVE CERVICAL SAGITTAL ALIGNMENT ON POSTOPERATIVE SURGICAL RESULTS IN PATIENTS TREATED BY ANTERIOR CERVICAL DISCECTOMY AND FUSION
}

\author{
(1) Canan SUBAȘI ${ }^{1}$, (1) Cengiz TUNCER ${ }^{1}$, (1) Uygur ER² \\ ${ }^{1}$ Düzce University Faculty of Medicine, Department Neurosurgery, Düzce, Turkey \\ 2 Private Practice, Clinic of Neurosurgery, Ankara, Turkey
}

Objective: Cervical degenerative disc diseases arise in some degenerative settings. These degenerative cervical changes may be a consequence of cervical sagittal malalignment. The aim of this study is to assess preoperative profile and postoperative changes in cervical sagittal profiles; and correlation between these changes and surgical outcomes in patients undergoing anterior cervical discectomy and fusion.

Materials and Methods: Eighty consecutive men and women who underwent anterior cervical discectomy and fusion (ACDF) were enrolled in the study. Cervical alignment was classified into 4 types-lordotic, flat, sigmoid, and kyphotic. Lordosis angle was measured by the Cobb method. Segmental angle at the level of discectomy was measured. Preoperative, early postoperative, and the $1^{\text {st }}$ and $3^{\text {rd }}$ month visual analog scale results were recorded. Improvement of cervical sagittal alignment and visual analogue scale (VAS) changes were compared statistically.

Results: The median preoperative VAS score was 7. This score decreased to 1 as a median immediately after operation. This change was statistically significant. Sagittal alignment changes in early postoperative period were not statistically significant despite the observation of improvement in some patients. However, after $1^{\text {st }}$ and $3^{\text {rd }}$ months, results showed significant improvements.

Conclusion: ACDF is an effective treatment of cervical degenerative disc diseases (CDDD). Decompression is still the main issue of the degenerative cervical diseases. Sagittal alignment may be restored by using lordotic cages. Patients with F sagittal shape may tend to develop CDDD more than $\mathrm{N}$ sagittal profile. There is a correlation between clinical improvement and radiologic improvement.

Keywords: Cervical sagittal alignment, anterior cervical discectomy and fusion, cervical spine, surgery Level of Evidence: Level II, Retrospective randomized study

\section{INTRODUCTION}

Normal cervical vertebral column is lordotic in shape. Many authors in the literature define normal cervical lordosis angle to be between $20^{\circ}$ and $35^{\circ}(6,7,16)$. Cervical lordosis creates stimulus to normal development of Lusckha joints and this is vital for appropriate cervical integrity ${ }^{(12)}$. Normal cervical alignment is important for appropriate axial loading to the vertebrae, facet joints, discs, and ligaments. It also affects cervical range of motion and general cervical kinematic ${ }^{(9,15)}$. In the literature, there are some studies on that decrease in cervical lordosis or flat cervical alignment and cervical kyphosis can cause cervical degenerative diseases by asymmetric loading(3,10). At the same time, there are also some authors that claim that existing kyphotic cervical deformity or even loss of some degree cervical lordosis may affect surgical outcomes after posterior cervical approaches for various cervical spine pathologies ${ }^{(13)}$. It is also widely accepted that cervical degenerative disc diseases (CDDD) arise in some degenerative settings. These degenerative cervical changes may be a consequence of cervical sagittal malalignment and vice versa ${ }^{(5)}$. The aim of this study is to assess preoperative profile and postoperative changes in cervical sagittal plane alignments and correlation between these changes and surgical outcomes in patients undergoing anterior cervical discectomy and fusion (ACDF).

\section{MATERIALS AND METHODS}

\section{Study Population}

Eighty consecutive men and women who underwent ACDF at three or less levels were enrolled in the study. Patients aged $>18$ years who had 1,2 or three levels soft cervical disc hernia were included in the study. Patients who had previous cervical operations, structural bony anomaly, deformity, metabolic 
bone diseases, any other metabolic diseases such as diabetes or thyroid diseases, or any malignancy, cervical spinal canal narrowing or any other bony pathology affecting the canal or foramens and patients with spondylotic myelopathy were not included. Obese patients with body mass index $>30 \mathrm{~kg} /$ $\mathrm{m}^{2}$, pregnant patients, and patients with traumatic disc hernias were also not included.

All patients were evaluated for operation indications by 2 surgeons separately in a blinded fashion. Preoperative neurologic examinations of patients were performed also by two surgeons separately. All operations were performed by the senior author (U.E.).

\section{Operation}

All patients were performed standard anterior ACDF with a PolyEther-Ether-Ketone (PEEK) cage under the operation microscope with microinstruments. A right side anterior transvers incision was used. An image intensifier was peroperatively used for determining and checking vertebral level. The posterior longitudinal ligament was removed segmentally and anterior side of the dura was seen. Both end plates were curetted gently after the intervertebral disc was removed. PEEK cages that were used for all patients were lordotic and bladed type with different size.

\section{Radiologic Evaluation}

All lateral cervical roentgenograms must show basis cranium, all 7 cervical vertebrae and at least upper side of the first thoracic vertebra. Cervical alignment was classified into 4 types-lordotic, flat, sigmoid and kyphotic-according to the Toyama classification ${ }^{(14)}$. Lordosis angle was measured between C2 inferior end plate and C7 superior end plate by the Cobb method $^{(4)}$. Segmental angle at the level of discectomy was measured.

\section{Pain Evaluation}

Preoperative, early postoperative, the $1^{\text {st }}$ and $3^{\text {rd }}$ month visual analogue scale (VAS) results were recorded.

\section{Statistical Analysis}

Statistical analysis was performed by using a software (SPSS vs. 22 , IBM, USA). The convenience of data was evaluated by the Shapiro-Wilks test. Demographic comparison of two groups was performed by the independent Samples t-test; and VAS comparison between two groups was done by the MannWhitney $\mathrm{U}$ test. The Wilcoxon signed-rank test was used for the comparison of VAS values in each group. Sagittal alignment was compared by using the McNemar-Bowker test. Any p value $<0.05$ was considered as significant.

\section{RESULTS}

Thirty eight men and 42 women were enrolled the study. The mean age of the patients was $46.99 \pm 9.47$ years with a range of 27-69 years. There was no significant difference between the mean ages of the men and women. The median preoperative VAS score was 7. This score decreased to 1 as a median immediately after the operation. This change was statistically significant $(p<0.001)$. There were no differences between both genders in terms of VAS changes. Twenty patients had a normal cervical lordosis $(\mathrm{N})$ according to the Toyama types ${ }^{(11)}$ preoperatively, 42 patients had flat cervical (F) alignment, 11 patients had kyphotic cervical alignment (K), and 7 patients had sigmoid cervical profile $(\mathrm{S})$. There was no gender differences with regard to cervical alignment types preoperatively $(p=0.553)$. Table 1 shows changes in cervical alignments. Sagittal alignment changes in early postoperative period were not statistically significant $(p=0.099)$ despite the observation of improvement in some patients. However, after $1^{\text {st }}$ and $3^{\text {rd }}$ months, results showed significant improvements with $p$ values of 0.022 and 0.023 , respectively. Overall complication rate of this series was $5 \%$. Hoarseness was seen in 2 patients, Horner's syndrome in one patient, and temporary dysphagia in one patient.

Table 1. Changes in cervical sagittal alignment after anterior cervical discectomy and fusion

\begin{tabular}{lllll}
$\begin{array}{l}\text { Sagittal } \\
\text { Toyama } \\
\text { types } \\
(\mathrm{n}=80)\end{array}$ & Preoperative & $\begin{array}{l}\text { Early } \\
\text { preoperative }\end{array}$ & $\begin{array}{l}1^{\text {st }} \\
\text { month }\end{array}$ & $\begin{array}{l}3^{\text {rd }} \\
\text { month }\end{array}$ \\
\hline L & 20 & 24 & 34 & 35 \\
\hline F & 42 & 48 & 40 & 39 \\
\hline K & 11 & 6 & 4 & 3 \\
\hline S & 7 & 2 & 2 & 3 \\
\hline
\end{tabular}

L: Lordotic cervical sagittal shape, F: Flat cervical sagittal shape, $\mathrm{K}$ : Kyphotic cervical sagittal shape, S: Sigmoid cervical sagittal shape

\section{DISCUSSION}

Cervical curve is a secondary spinal curve that provides compensation to the other spine curves which are on the sagittal plane. As the upper curve of the thoracic kyphosis, normal cervical alignment is lordotic with a range of $10^{\circ}$ $30^{\circ(8)}$. In order to maintain horizontal gaze in erect position, orientation of the atlanto-occipital joints must be horizontal in direction. Cervical lordosis provides the orientation of these joints with minimum energy expenditure. If the cervical lordosis is lost, more energy would be needed to maintain horizontal gaze. Loss of cervical lordosis may be the first step of CDDD. That seventy five percent of the patients treated by ACDF in this series had loss of cervical lordosis may strengthen this opinion. In a study in the literature, it was reported that the rate of losing cervical lordosis was lower than in patients with neck pain which did not need operative treatment ${ }^{(5)}$.

If the main hypothesis of this study is confirmed, cervical sagittal alignment of the patients will improve in some degree, which is demonstrated with the retrospective analysis of patients' sagittal profile changes after operation. Forty two patients had $\mathrm{F}$ type cervical alignment preoperatively; $\mathrm{N}$ sagittal alignment was seen in $21.4 \%$ in early postoperative 
period. $\mathrm{N}$ alignment was seen in the first month in $45.2 \%$ and in the third month in $52.4 \%$ cumulatively. Eleven patients had $\mathrm{K}$ type cervical alignment preoperatively; $\mathrm{F}$ cervical alignment, 1 step improvement, was seen in $54.5 \%$ in early postoperative period. After the $1^{\text {st }}$ month, $72.7 \%$ of these patients showed 1 or 2 step improvement, namely $\mathrm{F}$ or $\mathrm{N}$ sagittal alignment. After the $3^{\text {rd }}$ month, this improvement reached to $81.8 \%$. Seven patients had $\mathrm{S}$ type cervical alignment preoperatively; $\mathrm{F}$ or $\mathrm{N}$ type cervical alignment was seen in $85.7 \%$ in early postoperative period. After the $1^{\text {st }}$ month, all of them showed $\mathrm{F}$ or $\mathrm{N}$ type sagittal profile. These results confirm that the main hypothesis of this study may be correct. At the same time, clinic results of these radiologic improvements were investigated with VAS scores. In all groups, VAS changes were significant $(p<0.001)$ in early postoperative period (Table 2). Despite the excellent results after this operative technique, adding fusion to the simple anterior cervical discectomy brings new complications ${ }^{(1)}$. Surgical experience gained in years may decrease the complication rate. Overall complication rate of this series was low and the complications were minor. Surgical techniques and experience are two important factors for this low rate. All the posterior osteophytes and ligamentous remnants that may compress the neural tissue can be removed under surgical microscope with microinstruments. Even if PLL is intact, we advocate open and remove it. After removing the PLL, we saw some sequestrated fragments under the PLL in some cases. Some authors have claimed that folding and swelling of the PLL is the main reason of reexpolarations for morbidities in early postoperative period(2). One of the main results of this study is that restoration of the cervical sagittal alignment may influence the result of ACDF. Lordotic cages may provide this restoration in some degree. At the same time, cages provide the preservation of intervertebral high. This may prevent secondary root compression and anterior column shortness. Another important result of the study is that the cervical degenerative changes, mainly disc diseases may develop easily in the abnormal sagittal alignment because the adjustment of horizontal gaze needs more energy and strain due to use of forces to the opposite direction of the disordered alignment. These two important results were obtained mainly in early

Table 2. Changes in visual analogue scale immediately after anterior cervical discectomy and fusion

\begin{tabular}{llll}
\hline $\begin{array}{l}\text { Sagittal } \\
\begin{array}{l}\text { Toyama types } \\
(n=80)\end{array}\end{array}$ & $\begin{array}{l}\text { Preoperative } \\
\text { VAS mean }\end{array}$ & $\begin{array}{l}\text { Early preoperative } \\
\text { VAS mean }\end{array}$ & $p$ \\
\hline$L(n=20)$ & 6 & 1 & $<0.001$ \\
\hline$F(n=42)$ & 7 & 1 & $<0.001$ \\
\hline$K(n=11)$ & 7 & 1 & $<0.001$ \\
\hline$S(n=7)$ & 6 & 1 & $<0.001$ \\
\hline
\end{tabular}

VAS: Visual analogue scale, L: Lordotic cervical sagittal shape, F: Flat cervical sagittal shape, K: Kyphotic cervical sagittal shape, S: Sigmoid cervical sagittal shape postoperative period; and improvements of sagittal alignment continue in midterm postoperative period. This event may be considered as a supporting factor of this opinion.

A minor result of this study is that the $F$ type cervical sagittal alignment is seen frequently in patients with CDDD who were treated operatively. This event is not considered as structural. It may be largely restored after ACDF. F type cervical alignment may arise from paravertebral muscle spasms, and this may be a worsening factor for CDDD. Regardless of the preoperative situation of the patients or their radiologies, pain perceptions of the patients were decreased significantly. Decompression is still the main issue of the degenerative cervical diseases. The low complication rate of this series shows that ACDF is an effective operation for the treatment of CDDD.

\section{CONCLUSION}

ACDF is an effective treatment of CDDD. Decompression is still the main issue of the degenerative cervical diseases. Sagittal alignment may be restored by using lordotic cages. Patients with $F$ sagittal shape may tend to develop CDDD more than those with $\mathrm{N}$ sagittal profile. There is a correlation between clinical improvement and radiologic improvement.

\section{Ethics}

Ethics Committee Approval: This study was approved by the local ethics committee of Düzce University.

Informed Consent: A written informed consent were obtained from all patients.

Peer-review: Internally peer-reviewed.

\section{Authorship Contributions}

Surgical and Medical Practices: U.E., Concept: C.S., Design: U.E., C.S., Data Collection or Processing: C.S., C.T., Analysis or Interpretation: U.E., C.S., Literature Search: C.S., C.T., Writing: C.S., U.E.

Conflict of Interest: No conflict of interest was declared by the authors.

Financial Disclosure: The authors declared that this study received no financial support.

\section{REFERENCES}

1. Aronson N, Bagan M, Filtzer DL. Results of using the Smith-Robinson approach for herniated and extruded cervical discs. Technical note. J Neurosurg 1970;32:721-2.

2. Bertalanffy H, Eggert HR. Complications of anterior cervical discectomy without fusion in 450 consecutive patients. Acta Neurochir (Wien) 1989;99:41-50.

3. Breig A. Adverse mechanical tension in the central nervous system: An analysis of cause and effect: Relief by functional neurosurgery: J Wiley 1978.

4. Cobb J. Outline for the study of scoliosis. Instr Course Lect 1948;5:261-75.

5. Erdin Ç, Er U, Tuncer C. Altering of cervical sagittal parameters after 1 or 2 levels of anterior cervical discectomy and fusion with lordotic cages. Short term results. JTSS 2018;28:169-74.

6. Gay RE. The curve of the cervical spine: variations and significance. 
turkishspine

Manipulative Physiol Ther 1993:591-4.

7. Gore DR, Sepic SB, Gardner GM. Roentgenographic findings of the cervical spine in asymptomatic people. Spine 1986;11:521-4.

8. Guo GM, Li J, Diao QX, Zhu TH, Song ZX, Guo YY, et al. Cervical lordosis in asymptomatic individuals: a meta-analysis. J Orthop Surg Res. 2018;13:147-54.

9. Harrison DD, Janik TJ, Troyanovich SJ, Holland B. Comparisons of lordotic cervical spine curvatures to a theoretical ideal model of the static sagittal cervical spine. Spine 1996;21:667-75.

10. Lennon J, Shealy N, Cady RK, Matta W, Cox R, Simpson WF. Postural and respiratory modulation of autonomic function, pain, and health. Am J Pain Manag 1994;4:36-9.

11. Okada E, Matsumoto $M$, Ichihara D, Chiba C, Toyama Y, Fujiwara H, et al. Does the sagittal alignment of the cervical spine have an impact on disk degeneration? Minimum 10-year follow-up of asymptomatic volunteers. Eur Spine J 2009;18:1644-51.
12. Panjabi MM, Oda T, Crisco JJ, Dvorak J, Grob D. Posture affects motion coupling patterns of the upper cervical spine. J Orthop Res 1993; 11:525-36.

13. Şimşek S, Er U, Yiğitkanlı K. Relation between cervical sagittal alignment and surgical outcome for laminectomy and posterior fusion operations. JTSS 2017; 28:15-20.

14. Toyama $\mathrm{Y}$, Hirabayashi $H$, Kamata $M$. Long-term clinical result of anterior interbody fusion for cervical spondylotic myelopathy [in Japanese]. East Jpn J Orthop Traumatol 1997:487-92.

15. Walmsley RP, Kimber P, Culham E. The effect of initial head position on active cervical axial rotation range of motion in two age populations. Spine 1996;21:2435-42.

16. Xu-hui Z, Jia-hu F, Lian-shun J, Zhi-yong C, Yong Z, Xiong-sheng C, et al. Clinical significance of cervical vertebral flexion and extension spatial alignment changes. Spine 2009;34:E21-E6. 